\title{
ALTOS NÍVEIS DIETÉTICOS DE COBRE NO DESEMPENHO E NO COLESTEROL SÉRICO E MUSCULAR DE FRANGOS DE CORTE
}

\author{
Sonia Cristina Daróz de Morais',3; José Fernando Machado Menten ${ }^{2,3 *}$; Mônica Maria de \\ Almeida Brainer'; Marcos Martinez do Vale ${ }^{4}$ \\ ${ }^{1}$ Pós-Graduanda do Depto. de Produção Animal - USP/ESALQ. \\ ${ }^{2}$ Depto. de Produção Animal - USP/ESALQ, C.P. 9 - CEP: 13418-900 - Piracicaba, SP. \\ ${ }^{3}$ Bolsista CNPq. \\ ${ }^{4}$ Bolsista CAPES. \\ *Autor correspondente <jfmmente@carpa.ciagri.usp.br>
}

RESUMO: O cobre, em níveis supranutricionais nas dietas de frangos de corte, atua como promotor do crescimento. Para avaliar as respostas no desempenho e no colesterol sérico e muscular de frangos de corte, 1200 pintos (600 machos e 600 fêmeas) receberam rações suplementadas com 50, 100 ou $150 \mathrm{mg} \mathrm{kg}^{-1}$ de cobre como citrato cúprico, ou $200 \mathrm{mg} \mathrm{kg}^{-1}$ de cobre como sulfato cúprico pentahidratado, ou uma dieta controle, não suplementada, em um experimento em blocos casualizados com três repetições e arranjo fatorial de cinco tratamentos e dois sexos. As rações, baseadas em milho e farelo de soja e adequadas em todos os nutrientes (12 mg kg-1 de cobre na dieta controle), e água foram fornecidas à vontade durante o experimento de 42 dias. Não houve efeito $(P>0,05)$ de tratamentos nas variáveis ganho de peso, consumo de ração $(C R)$, conversão alimentar $(C A)$ e mortalidade + refugagem $(M+R)$ nos períodos de 1 a 21 dias e de 22 a 42 dias, com valores médios de 0,778 e 1,501 kg para GP, 1,181 e 3,087 kg para CR, 1,540 e 2,060 para CA, 1,42 e $2,08 \%$ para $M+R$, respectivamente. Ao final do experimento o peso vivo (2,310 kg), o ganho de peso diário (55 g), o fator de produção (282,2), o colesterol no soro sangüíneo (129 $\mathrm{mg} \mathrm{dL}^{-1}$ ) e o colesterol no músculo $\left(55,9 \mathrm{mg} 100 \mathrm{~mL}^{-1}\right)$ também não foram afetados pelos tatamentos $(P>0,05)$. Os machos e as fêmeas tiveram níveis semelhantes de colesterol $(P>0,05)$ no soro e no músculo.

Palavras-chave: citrato cúprico, colesterol, frango de corte, promotor de crescimento, sulfato cúprico

\section{HIGH DIETARY COPPER LEVELS ON THE PERFORMANCE AND SERUM AND MUSCLE CHOLESTEROL OF BROILER CHICKEN}

\begin{abstract}
High copper feeding, is used as a growth promoter of broiler chickens. Performance as well as serum and muscle cholesterol of 1200 broiler chickens (600 male and 600 female) which were fed diets supplemented with 50, 100 or 150 mg copper kg-1 (as cupric citrate), or $200 \mathrm{mg}^{-1}$ copper $\mathrm{kg}^{-1}$ (as cupric sulfate pentahydrate), or an unsupplemented control diet were determined in an experiment of $5 \times 2$ complete randomized blocks with 3 replicates (5 treatments and 2 sexes). The feeds, based on corn and soybean meal and adequate in all nutrients (12 $\mathrm{mg}$ copper $\mathrm{kg}^{-1}$ in the control diet), and water were supplied ad libitum during the 42 day experimental period. There were no effects $(P>0.05)$ of treatments on weight gain $(W G)$, feed intake $(F I)$, feed/gain ratio $(F / G)$ and mortality + culling $(M+C)$ during 1 to 21 or 22 to 42 days; the averages were 0.778 and $1.501 \mathrm{~kg}$ for $W G, 1.181$ and $3.087 \mathrm{~kg}$ for $\mathrm{Fl}, 1.540$ and 2.060 for $F / G$ and 1.42 and $2.08 \%$ for $M+C$, respectively. At the end of the trial the liveweight $(2.310 \mathrm{~kg})$, the average daily gain $(55 \mathrm{~g})$, the production index (282.2), the serum cholesterol (129 mg dL ${ }^{-1}$ ) and breast muscle cholesterol (55.9 mg $\left.100 \mathrm{~g}^{-1}\right)$ were not affected by treatments either $(P>0.05)$. Male broilers were superior to the females $(P<0.05)$ in the performance traits (liveweight 2.530 vs $2.090 \mathrm{~kg} ; \mathrm{F} / \mathrm{G} 1.85$ vs 1.90), but the cholesterol levels in serum and muscle were similar across sexes $(P>0.05)$.
\end{abstract}

Key words: broiler chickens, cholesterol, copper sulfate, cupric citrate, growth promoter

\section{INTRODUÇÃO}

A suplementação com níveis elevados de cobre, como promotor de crescimento, nas dietas de frangos de corte constitui uma alternativa interessante aos aditivos usualmente utilizados. Os níveis de cobre sugeridos como tendo efeito promotor de crescimento (125 a $250 \mathrm{mg} \mathrm{Cu}$ $\mathrm{kg}^{-1}$ ) são muito mais elevados que os $8 \mathrm{mg} \mathrm{Cu} \mathrm{kg}{ }^{-1}$ necessários para atender as exigências nutricionais (NRC, 1994). O sulfato cúprico pentahidratado é a fonte de cobre mais usada na indústria de rações. Além disso, o sulfato cúprico tem sido utilizado há muitos anos na avicultura no tratamento de enterites e vários tipos de micoses (Schaible, 1970).

Outras fontes de cobre têm sido pesquisadas: Hoda \& Maha (1995) avaliaram a eficiência do cobre como promotor de crescimento em dietas para frangos de corte nas formas de carbonato cúprico, óxido cúprico e sulfato cúprico, empregando níveis de 75 e $150 \mathrm{mg} \mathrm{kg}^{-1}$. Os autores observaram que ambos os níveis de suplementação de carbonato cúprico e 150 ppm de sulfato cúprico aumentaram significativamente o ganho de peso e melhoraram a conversão alimentar, enquanto que o óxido cúprico não apresentou efeito promotor de crescimento. 
Mais recentemente, o citrato cúprico foi estudado como promotor de crescimento de frangos de corte em uma série de trabalhos na Universidade da Georgia (Pesti \& Bakalli, 1996; Ewing et al., 1998). Os autores observaram que utilizando citrato cúprico como promotor de crescimento na ração, aos níveis de 63 ou $75 \mathrm{mg} \mathrm{Cu} \mathrm{kg}^{-1}$, ele apresentou-se mais eficiente pois proporcionou um melhor desempenho das aves quando comparado ao sulfato cúprico pentahidratado, empregado nos níveis de 125 e $250 \mathrm{mg} \mathrm{Cu} \mathrm{kg}^{-1}$. Ewing et al. (1998) também utilizaram oxicloreto de cobre, relatando que as formas sulfato cúprico e oxicloreto de cobre aumentaram em $4,9 \%$ o ganho de peso, enquanto que o citrato cúprico aumentou em 9,1\%. Como a disponibilidade de Cu na maior parte das fontes é baixa (McDowell, 1992), Pesti \& Bakalli (1996) propuseram que a maior eficácia do citrato cúprico é devida a sua maior absorção.

Um outro aspecto que tem sido estudado é o efeito do cobre sobre o metabolismo de lipídios e a concentração de colesterol no organismo. Bakalli et al. (1995) demonstraram que a deficiência de cobre causou hipercolesterolemia e que a suplementação de $250 \mathrm{mg}$ de $\mathrm{Cu} \mathrm{kg}{ }^{-1}$ de ração de frangos de corte, como sulfato cúprico, promoveu a redução do colesterol total do plasma ( 26\%), o aumento do HDL colesterol ( 11\%), a redução dos triglicerídios no plasma ( 43\%), a redução da glutationa no sangue $(\sim 40 \%)$ e a redução do colesterol do músculo do peito ( 27\%). Pesti \& Bakalli (1996) obtiveram reduções do colesterol plasmático e do músculo do peito ainda maiores com o uso de citrato cúprico, mesmo com níveis mais baixos de $\mathrm{Cu}$, quando comparado com o sulfato cúprico. Konjufca et al. (1997) relataram reduções do colesterol dos músculos do peito e da coxa em $24 \%$ e $22 \%$, respectivamente, quando as rações continham alto nível de cobre.

Brainer (1998) avaliou a eficiência do cobre como promotor de crescimento de frangos de corte, suplementando cobre nas rações nos períodos de 1-42 dias, 1-21 dias e 2242 dias, nas formas de citrato cúprico $\left(75 \mathrm{mg} \mathrm{Cu} \mathrm{kg}^{-1}\right)$ e sulfato cúprico pentahidratado $\left(200 \mathrm{mg} \mathrm{Cu} \mathrm{kg}^{-1}\right)$. A autora não verificou efeito significativo do cobre suplementar sobre o desempenho, nem diferenças entre as duas formas de cobre utilizadas.

O presente estudo foi realizado para avaliar o efeito promotor de crescimento de níveis crescentes de citrato cúprico em comparação ao sulfato cúprico pentahidratado nas rações de frangos de corte, bem como o efeito dessas fontes de cobre sobre a concentração de colesterol no músculo do peito e no plasma.

\section{MATERIAL E MÉTODOS}

O experimento foi instalado em um aviário contendo 30 parcelas, usando maravalha como material de cama. O aquecimento foi feito com lâmpadas infravermelhas; os comedouros eram do tipo tubular e os bebedouros eram do tipo pendular. Foram utilizados 1200 pintos de corte de um dia de idade, da linhagem HubbardPeterson, sendo 600 machos e 600 fêmeas, alojados em grupos de 40 aves sexadas por parcela. Ração e água foram fornecidas à vontade e a iluminação foi constante.

Os tratamentos realizados foram: (1) CONT (controle negativo) $=$ Dieta basal $(D B)$ adequada em todos os nutrientes e contendo 12 mg de Cu suplementar/kg de ração; (2) CITR. 50, (3) CITR. 100 e (4) CITR. $150=$ DB suplementada com 50, 100 e $150 \mathrm{mg} \mathrm{Cu} \mathrm{kg}^{-1}$ de ração, respectivamente, na forma de citrato cúprico e (5) SULF. 200 (controle positivo) = DB suplementada com $200 \mathrm{mg} \mathrm{Cu} \mathrm{kg}^{-1}$ de ração, na forma de sulfato cúprico pentahidratado.

As rações das fases inicial (1 a 21 dias), crescimento (22 a 35 dias) e final (36 a 42 dias) foram formuladas de acordo com Rostagno et al. (1994) e estão apresentadas na TABELA 1. As fontes de cobre adicionadas às rações foram o citrato cúprico anidro, contendo $37,38 \%$ de cobre e o sulfato cúprico pentahidratado, contendo $25,0 \%$ de cobre.

TABELA 1 - Composição percentual e valores calculados das dietas basais.

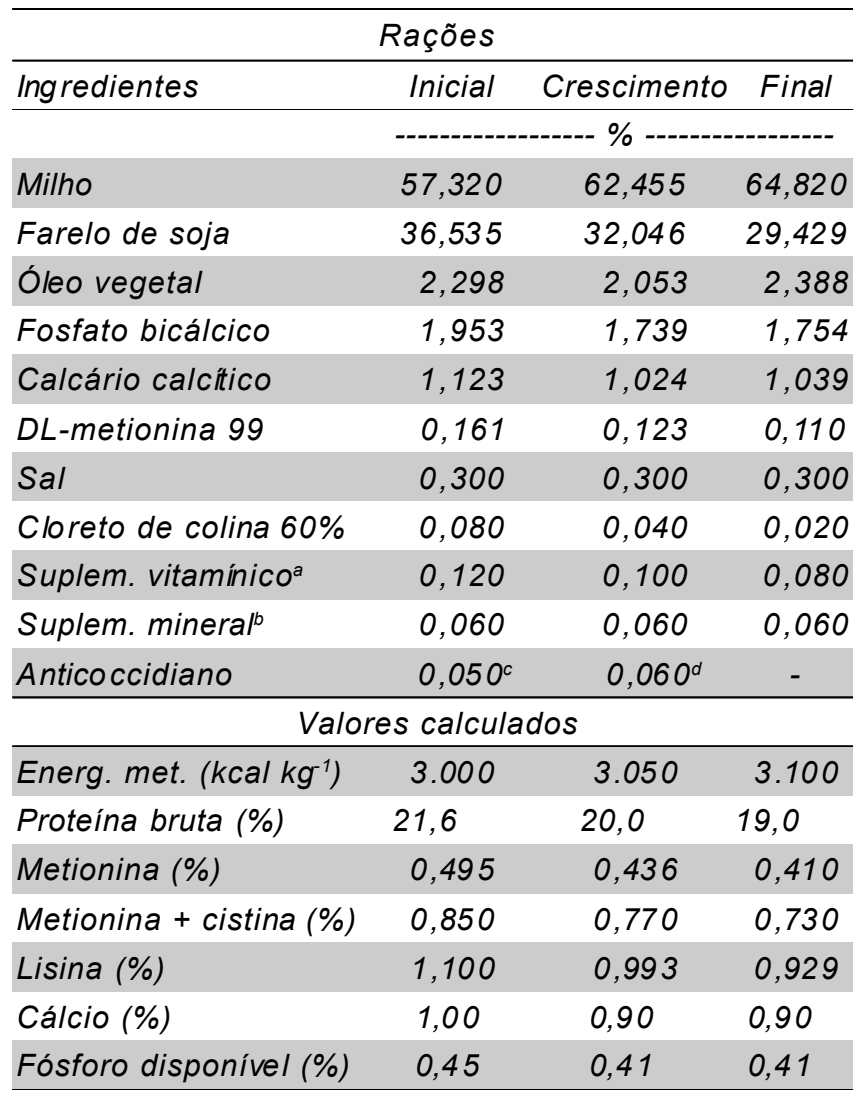

${ }^{a}$ Cada kg do suplem. vitamínico contém: vit. A, 10.000.000 Ul; vit. $D_{3}, 2.000 .000 \mathrm{UI}$; vit. $E, 30.000 \mathrm{Ul}$; vit. $K_{3}, 3.000 \mathrm{mg}$; vit. $B_{1}, 2.000$ $\mathrm{mg}$; vit. $B_{2}, 6.000 \mathrm{mg}$; vit. $B_{6}, 4.000 \mathrm{mg}$; vit. $B_{12}, 15.000 \mathrm{mcg}$; ác. nicotínico, $50.000 \mathrm{mg}$; ác. pantotênico, $12.000 \mathrm{mg}$; biotina, $100 \mathrm{mg}$; ác. fólico, $1.000 \mathrm{mg}$; selênio, $250 \mathrm{mg}$; veículo q.s.p., $1.000 \mathrm{mg}$.

${ }^{b} \mathrm{Cada} \mathrm{kg}$ do suplem. mineral contém: cobalto, $2.000 \mathrm{mg}$; iodo, 2.000 $\mathrm{mg}$; manganês, $16.000 \mathrm{mg}$; ferro, $100.000 \mathrm{mg}$; cobre, $20.000 \mathrm{mg}$; zinco, $100.000 \mathrm{mg}$.

${ }^{\circ} \mathrm{Cada} 1.000 \mathrm{~g}$ de anticoccidiano contém: maduramicina $7,5 \mathrm{~g}$; nicarbazina $80 \mathrm{~g}$; veículo q.s.p., $1000 \mathrm{~g}$.

${ }^{d}$ Cada $1.000 \mathrm{~g}$ de anticoccidiano contém: lasalocida sódica $150 \mathrm{~g}$; veículo q.s.p., $1.000 \mathrm{~g}$. 
O delineamento experimental foi em blocos casualizados em arranjo fatorial $5 \times 2$, constituído de 5 dietas e 2 sexos, com 3 repetições.

Semanalmente foram feitas pesagens das aves e das rações consumidas no período, sendo determinadas as variáveis, ganho de peso (GP), consumo de ração $(C R)$, conversão alimentar (CA) e mortalidade + refugagem $(M+R)$. Essas variáveis foram calculadas para os períodos de 1-21 dias, 22-42 dias e 1-42 dias de idade. O peso vivo (PV), o ganho de peso diário (GPD) e o fator de produção (FP) foram calculados para o período total do experimento.

Ao final do experimento, logo após a pesagem das aves, foi escolhida uma ave representativa da média da parcela para a coleta de sangue; uma amostra de aproximadamente $3 \mathrm{~mL}$ de sangue foi retirada da veia ulnar em seringa descartável, sendo usada agulha $25 \times 7$, transferida para tubo sem qualquer anticoagulante, mantida em gelo e centrifugada para retirada do soro. As mesmas aves foram abatidas por deslocamento cervical, sem jejum prévio, sendo o músculo do peito retirado, mantido em gelo e em seguida congelado. O colesterol no soro sangüíneo (ColS.) foi determinado em laboratório de análises clínicas, sendo usado o Teste Colorimétrico Enzimático Hitachi-911. O colesterol no músculo (ColC.) foi determinado no Instituto de Tecnologia de Alimentos (ITAL) através de Cromatografia Líqüida de Alta Eficência, segundo o método de Bragagnolo \& Rodriguez-Amaya (1992).

Os resultados foram analisados utilizando o Programa SAS (Statistical Analyses System) de análises estatísticas. Os dados de desempenho (GP, CR, CA e $M+R)$ foram submetidos à análise da variância nos períodos de 1 a 21 dias, de 22 a 42 dias e no período total de 1 a 42 dias. Suas médias foram comparadas através do teste de Tukey, ao nível de 5\% de significância. Os resultados de PV, ColS., ColC., GPD e FP foram obtidos apenas aos 42 dias, e foram submetidos às mesmas análises estatísticas empregadas para os resultados de desempenho.

\section{RESULTADOS E DISCUSSÃO}

Não houve diferença $(P>0,05)$ entre as médias das variáveis $G P, C R$ e CA para o fator tratamento, indicando que a suplementação de níveis elevados de citrato cúprico ou de sulfato cúprico pentahidratado não tiveram efeito sobre o desempenho das aves (TABELA 2). Os resultados de $M+R$ foram baixos (média de 1,42\%), não sendo afetados pelos tratamentos $(P>0,05$, dados não apresentados).

Quando analisado o efeito de sexo, houve diferença $(P<0,05)$ entre as médias das variáveis $G P, C R$ e CA. Porém, este resultado já era esperado, uma vez que é conhecido que os machos têm melhor desempenho do que as fêmeas. Para a variável $M+R$ não houve diferença entre sexos $(P>0,05)$.

Não houve diferença $(P>0,05)$ entre as médias das variáveis $G P, C R$ e CA para o fator tratamento, indicando que os níveis elevados de citrato cúprico assim como de sulfato cúprico pentahidratado não tiveram efeito sobre o desempenho das aves (TABELA 3). Neste período, os resultados de $M+R$ foram de $2,08 \%$, em média, não havendo efeito de tratamentos $(P>0,05$, dados não apresentados).

Assim como no período anterior, quando analisado o efeito de sexo, houve diferença $(P<0,05)$ entre as médias das varáveis $G P, C R$ e $C A$, indicando o desempenho superior dos machos, mas não houve diferença $(P>0,05)$ para a variável $M+R$.

TABELA 2 - Efeito dos tratamentos sobre as variáveis ganho de peso (GP), consumo de ração (CR) e conversão alimentar (CA) no período de 1 a 21 dias da criação das aves.

\begin{tabular}{lcccc}
\hline Tratamentos Sexo & GP & CR & $C A$ \\
\hline \multirow{4}{*}{ CONTR. } & fêmea & $0,721^{a}$ & $1,121^{a}$ & $1,555^{a}$ \\
& macho & $0,825^{b}$ & $1,237^{b}$ & $1,500^{b}$ \\
CITR. 50 & fêmea & $0,714^{a}$ & $1,124^{a}$ & $1,574^{a}$ \\
& macho & $0,821^{b}$ & $1,225^{b}$ & $1,493^{b}$ \\
CITR. 100 & fêmea & $0,712^{a}$ & $1,153^{a}$ & $1,618^{a}$ \\
& macho & $0,808^{b}$ & $1,220^{b}$ & $1,509^{b}$ \\
CITR. 150 & fêmea & $0,716^{a}$ & $1,115^{a}$ & $1,557^{a}$ \\
& macho & $0,811^{b}$ & $1,239^{b}$ & $1,527^{b}$ \\
SULF. 200 & fêmea & $0,727^{a}$ & $1,121^{a}$ & $1,542^{a}$ \\
& macho & $0,824^{b}$ & $1,255^{b}$ & $1,523^{b}$ \\
\hline Coef. Var. (\%) & 1,70 & 1,69 & 1,79 \\
\hline
\end{tabular}

a, bMédias seguidas de letra de diferentes na coluna diferem pelo teste Tukey $(P<0,05)$.

TABELA 3 - Efeito dos tratamentos sobre as variáveis ganho de peso $(G P)$, consumo de ração $(C R) e$ conversão alimentar (CA) no período de 22 a 42 dias da criação das aves.

\begin{tabular}{lcccc}
\hline Tratamentos Sexo & GP & CR & CA \\
\hline \multirow{2}{*}{ CONTR. } & fêmea & $1,328^{a}$ & $2,794^{a}$ & $2,104^{a}$ \\
& macho & $1,679^{b}$ & $3,395^{b}$ & $2,023^{b}$ \\
CITR. 50 & fêmea & $1,337^{a}$ & $2,799^{a}$ & $2,093^{a}$ \\
& macho & $1,652^{b}$ & $3,364^{b}$ & $2,036^{b}$ \\
CITR. 100 & fêmea & $1,327^{a}$ & $2,807^{a}$ & $2,116^{a}$ \\
& macho & $1,687^{b}$ & $3,379^{b}$ & $2,003^{b}$ \\
CITR. 150 & fêmea & $1,342^{a}$ & $2,780^{a}$ & $2,071^{a}$ \\
& macho & $1,652^{b}$ & $3,355^{b}$ & $2,031^{b}$ \\
SULF. 200 & fêmea & $1,322^{a}$ & $2,773^{a}$ & $2,098^{a}$ \\
& macho & $1,688^{b}$ & $3,422^{b}$ & $2,028^{b}$ \\
\hline Coef. Var. (\%) & 2,50 & 1,76 & 1,42 \\
\hline
\end{tabular}

a, bMédias seguidas de letra de diferentes na coluna diferem pelo teste Tukey $(P<0,05)$. 
Não houve diferença $(P>0,05)$ entre as médias das variáveis de desempenho ( $P V, G P, C R, C A, G P D$ e FP) para o fator tratamento (TABELA 4), indicando, novamente, que a suplementação das dietas com níveis elevados de cobre não teve efeito sobre o desempenho das aves. Para as variáveis ColS. e ColC, quando analisado o efeito de tratamentos, também não foi detectada diferença $(P>0,05)$.

Quando analisado o efeito de sexo, houve diferença $(P<0,05)$ entre as médias das variáveis $P V, G P$, $C R, C A, G P D$ e FP, confirmando mais uma vez a diferença de desempenho entre os sexos. Para as variáveis Cols. e ColC. não houve diferença entre sexos $(P>0,05)$.

Pesti \& Bakalli (1996) demonstraram o efeito promotor de crescimento do cobre na ração de frangos de corte e observaram que o citrato cúprico foi mais eficiente em níveis mais baixos que os de sulfato cúprico pentahidratado. Neste trabalho foram utilizados tratamentos muito semelhantes aos do trabalho citado e não foi observada qualquer diferença de desempenho entre os tratamentos nos períodos estudados. Além do efeito sobre o ganho de peso, a conversão alimentar foi melhorada em $5,2 \%$ e $7,6 \%$ em dois experimentos com altos níveis de cobre desenvolvidos por Ewing et al. (1998); já no presente estudo não foi encontrado efeito sobre a conversão alimentar.

Os índices de desempenho obtidos neste estudo constituem uma evidência de que as condições gerais de criação foram muito boas, provavelmente com baixo desafio microbiano. O PV aos 42 dias (aproximadamente 2,1 kg para fêmeas e 2,5 kg para machos) e a CA (aproximadamente 1,90 para fêmeas e 1,85 para machos) podem ser considerados adequados. A ausência de desafio microbiano pode fornecer uma explicação para a falta de resposta no desempenho das aves suplementadas com com níveis elevados de Cu. Quando o sistema imunológico é estimulado, resulta em alterações metabólicas que diminuem a eficiência de utilização de nutrientes, provavelmente por alteração na absorção ou na taxa metabólica. A interleucina1 parece ser o mediador mais importante do estresse imunológico. Klasing et al. (1987) demonstraram que os níveis de interleucina-1 aumentaram após um estresse imunológico, e que injeções de interleucina-1 resultaram em redução no crescimento e na eficiência alimentar, além de alterações no metabolismo mineral.

Roura et al. (1992) sugeriram que o grau de higiene do ambiente afeta a ação dos antibióticos, os quais agem efetivamente reduzindo o estresse imunológico, através da diminuição da freqüência, da duração e/ou da intensidade do desafio microbiano e, consequentemente, da resposta imune. Os autores observaram pequeno efeito positivo do uso de antibióticos como promotores de crescimento em ambientes limpos. Porém, em ambiente com pouca higiene o aumento da taxa de crescimento e da eficiência alimentar, devido aos antibióticos, foi acompanhado pela redução dos niveis de interleucina-1 circulante, o que sugere que os antibióticos reduzem o estresse imunológico. Como a ação promotora de crescimento do cobre e de antibióticos parece ser semelhante, é possível supor que o baixo estresse imunológico neste estudo (proporcionado por longo vazio sanitário e cuidadosa limpeza e desinfecção e evidenciado pelo desempenho adequado) tenha mascarado o efeito promotor de crescimento. Outro parâmetro para avaliar as condições sanitárias do aviário são as taxas de mortalidade + refugagem que podem ser consideradas baixas, sendo estas de apenas $3,5 \%$.

Em outro estudo realizado nas mesmas instalações, Brainer (1998) também atribuiu às ótimas condições higiênicas das instalações o fato de o cobre não expressar sua capacidade promotora de crescimento.

TABELA 4 - Efeito dos tratamentos sobre as variáveis peso vivo (PV), ganho de peso (GP), consumo de ração (CR), conversão alimentar (CA), colesterol no soro (ColS.), colesterol no músculo (ColC.), ganho de peso diário (GPD) e fator de produção (FP) no período de 1 a 42 dias da criação das aves.

\begin{tabular}{|c|c|c|c|c|c|c|c|c|c|}
\hline Tratamentos & Sexo & $P V$ & $G P$ & $C R$ & $C A$ & Cols. & Colc. & $G P D$ & $F P$ \\
\hline & & ----------. & ----- kg - & ----------- & & $m g d L^{-1}$ & $m g 100 g^{-1}$ & $k g$ & \\
\hline \multirow[t]{2}{*}{ CONTR. } & fêmea & $2,089^{a}$ & $2,049^{a}$ & $3,915^{a}$ & $1,911^{a}$ & 127 & 53,8 & $0,050^{a}$ & $251,6^{a}$ \\
\hline & macho & $2,544^{b}$ & $2,503^{b}$ & $4,632^{b}$ & $1,850^{b}$ & 136 & 57,9 & $0,060^{b}$ & $316,5^{b}$ \\
\hline \multirow[t]{2}{*}{ CITR. 50} & fêmea & $2,093^{a}$ & $2,051^{a}$ & $3,923^{a}$ & $1,912^{a}$ & 120 & 53,1 & $0,050^{a}$ & $247,6^{a}$ \\
\hline & macho & $2,514^{b}$ & $2,473^{b}$ & $4,589^{b}$ & $1,856^{b}$ & 125 & 51,6 & $0,060^{b}$ & $317,2^{b}$ \\
\hline \multirow[t]{2}{*}{ CITR. 100} & fêmea & $2,080^{a}$ & $2,039^{a}$ & $3,960^{a}$ & $1,942^{a}$ & 152 & 56,4 & $0,049^{a}$ & $248,5^{a}$ \\
\hline & macho & $2,536^{b}$ & $2,496^{b}$ & $4,599^{b}$ & $1,843^{b}$ & 113 & 55,5 & $0,060^{b}$ & $311,2^{b}$ \\
\hline \multirow[t]{2}{*}{ CITR. 150} & fêmea & $2,100^{a}$ & $2,058^{a}$ & $3,895^{a}$ & $1,893^{a}$ & 138 & 58,1 & $0,050^{a}$ & $257,6^{a}$ \\
\hline & macho & $2,504^{b}$ & $2,464^{b}$ & $4,594^{b}$ & $1,865^{b}$ & 121 & 56,3 & $0,060^{b}$ & $303,6^{b}$ \\
\hline \multirow[t]{2}{*}{ SULF. 200} & fêmea & $2,091^{a}$ & $2,049^{a}$ & $3,894^{a}$ & $1,900^{a}$ & 138 & 59,4 & $0,050^{a}$ & $257,6^{a}$ \\
\hline & macho & $2,554^{b}$ & $2,513^{b}$ & $4,678^{b}$ & $1,862^{b}$ & 123 & 57,6 & $0,061^{b}$ & $310,3^{b}$ \\
\hline \multicolumn{2}{|l|}{ Coef. Var. (\%) } & 1,91 & 1,95 & 1,48 & 1,17 & 12,95 & 7,97 & 1,91 & 3,10 \\
\hline
\end{tabular}

a, bMédias seguidas de letra de diferentes na coluna diferem pelo teste Tukey $(P<0,05)$. 
Neste trabalho, quando analisadas as variáveis ColS. e ColC., os resultados obtidos diferiram daqueles em que foi obtida redução dos níveis de colesterol (Pesti \& Bakalli, 1996; Konjufca et al., 1997). Este fato provavelmente pode ser explicado por não ter havido diferença estatisticamente significativa de desempenho entre os tratamentos aplicados. Quando as aves têm maior ganho de peso, isto ocorre devido à maior deposição de proteínas, consequentemente há um aumento no tamanho das fibras musculares. É sabido que o colesterol está presente nas membranas. Quando ocorre o aumento da fibra muscular, há uma diminuição da concentração de colesterol por grama de tecido muscular. Uma possibilidade para explicar a ausência de efeito sobre o colesterol é que neste trabalho não houve diferença de desempenho entre os tratamentos aplicados, consequentemente também não foi possível identificar diferenças entre os níveis de colesterol no músculo.

\section{AGRADECIMENTOS}

À FAPESP pela concessão de Auxílio a Pesquisa para a realização deste trabalho.

\section{REFERÊNCIAS BIBLIOGRÁFICAS}

BAKALLI, R.I.; PESTI, G.M.; RAGLAND, W.L.; KONJUFCA, V. Dietary copper in excess of nutritional requeriment reduces plasma and breast muscle cholesterol of chickens. Poultry Science, v.74, p.360-365, 1995.

BRAGAGNOLO, N.; RODRIGUEZ-AMAYA, D.B. Teores de colesterol em carnes de frango. Revista de Farmácia e Bioquímica da Universidade de São Paulo, v.28, p.122-131, 1992.
BRAINER, M.M.A. Efeitos de citrato cúprico em diferentes fases de criação como promotor de crescimento de frangos de corte. Piracicaba, 1998. 81p. Dissertação (Mestrado) - Escola Superior de Agricultura "Luiz de Queiroz", Universidade de São Paulo.

EWING, H.P.; PESTI, G.M.; BAKALI, R.I.; MENTEN, J.F.M. Studies on the feeding of cupric sulfate pentahydrate, cupric sulfate, and copper oxychloride to broiler chickens. Poultry Science, v.77, p.445-448, 1998.

HODA, A.A.; MAHA, M.H. Potency of copper as growth promoter in broiler chickens. Veterinary Medical Journal, v.43, p.77-85, 1995.

KLASING, K.C.; LAURIN, D.E.; PENG, R.K.; FRY, D.M. Immunologically mediated growth depression in chicks: influence of feed intake, corticosterone and interleukin-1. Journal of Nutrition, v.117, p.1629-1637, 1987.

KONJUFCA, V.N.; PESTI, G.M.; BAKALLI, R.I. Modulation of cholesterol levels in broiler meat by dietary garlic and copper. Poultry Science, v.76, p.1264-1271, 1997.

McDOWELL, L.R. Minerals in animal and human nutrition. San Diego: Academic Press, 1992. cap.8, p.176-204: Copper and molybdenum.

NATIONAL RESEARCH COUNCIL. Nutrient requeriments of poultry. 9.ed. Washington: National Academic Press, 1994. 71p.

PESTI, G.M.; BAKALLI, R.I. Studies on the feeding of cupric sulfate pentahydrate and cupric citrate to broiler chickens. Poultry Science, v.75, p.1086-1091, 1996.

ROSTAGNO, H.S.; SILVA, D.J.; COSTA, P.M.A.; FONSECA, J.B.; SOARES, P.R.; PEREIRA, J.A.A.; SILVA, M.A. Composição de alimentos e exigências nutricionais de aves e suínos: tabelas brasileiras. Viçosa: UFV, 1994. 59p.

ROURA, E.; HOMEDES, J.; KLASING, K.C. Prevention of immunologic stress contributes to the growth-permitting ability of dietary antibiotics in chicks. Journal of Nutrition, v.122, p.2383-2390, 1992.

SCHAIBLE, P.J. Poultry: feeds and nutrition. Westport: The Avi Publishing, 1970. cap.16, p.250-282: Minerals.

Recebido em 25.11.99 